\title{
The Effects of Cognitive Appraisal and Emotion on Consumer Behavior: The Critical Role of Recollection in the Luxury Cruise Setting
}

Joo, Eunkyung ; Shin, Hyejin ${ }^{\text {a }}$; Kim, Insin ${ }^{a}$; Choi, Jinsung ; Jang, Junhwa ${ }^{\text {; }}$; Hun, Sunghyup Sean ${ }^{\mathrm{b}}$

${ }^{\mathrm{a}}$ Department of Tourism and Convention, Pusan National Univ, Republic of Korea; ${ }^{\mathrm{b}} \mathrm{School}$ of Tourism, Hanyang Univ., Republic of Korea

\begin{abstract}
The purposes of this study were: (1) to integrate the cognitive appraisal theory and script theory; (2) to examine the bonding character of recollection; and (3) to assess the relationships between consumers 'appraisals, positive/negative emotions, recollection, storytelling and repurchase intention. A review of previous studies revealed 14 theoretical hypotheses. The proposed hypotheses were tested utilizing data collected from 300 luxury cruise passengers. Confirmatory factor analysis and structural equation modeling were utilized to test the proposed theoretical relationships. According to the results, this work was the first to integrate the cognitive appraisal approach and script theory and also depicted a new angle from which marketers can better understand cruise travelers' behavior.
\end{abstract}

Keywords: Congnitive appraisal theory, script theory, emotions, recollection, luxury cruise. 